\title{
Study on Dust Control Technology in Artillery Working Face
}

\author{
Changfu ZOU ${ }^{1}$ \\ Chongqing Research Institute of China Coal Technology \& Engineering Group \\ Corporation, Chongqing, China
}

\begin{abstract}
Aiming at the serious problem of dust pollution in blasting work, the dust generation law and dust-bearing air flow time and space evolution law of blasting working face is analyzed and studied, and the optimal dust-exhausting wind speed of blasting work was $1.5 \mathrm{~m} / \mathrm{s}$. Combining with the dust production characteristics and wind speed conditions of the 107 blasting face in Dongling Coal Mine, Chongqing, Comprehensive dust prevention measures such as high-efficiency water cannon mud, high-pressure spray dust reduction, and dust concentration over-limit spray dust reduction are adopted to control the dust from the source and cut off the dust diffusion path, and the total dust reduction efficiency reached $94.8 \%$, the respirable dust reduction efficiency reached $92 \%$, and a good dust reduction effect has been achieved, which provides a basic basis for the control of dust in the blast mining work.
\end{abstract}

Keywords. Dust control technology, dust pollution, blasting

\section{Introduction}

In recent years, the dust generated by coal mine production has become a prominent problem affecting the health and safety of coal miners. In order to solve the dust hazards, many relevant researches have been done on dust control technology at home and abroad, but most of the research is suitable for machine mining. Machine excavation face, and the research on dust prevention and control of blasting face in small local coal mines in southern China is still in an earlier year, and its dust control is almost a blind spot for dust prevention [1-3]. As the country pays more attention to coal mine safety and occupational health and health, while continuing to carry out large and medium-sized coal mining machine mining dust control, research and application of dust prevention technology to solve the problem of dust hazards caused by blasting mining, is the coal mine dust in my country Important technical measures for prevention and treatment [46]. Based on the measured dust concentration of the blasting working face, this paper studies the dust diffusion law of the blasting working face, combined with the existing mature dust control technology of the machine digging face, and proposes targeted measures for the dust control of the blasting working face.

\footnotetext{
${ }^{1}$ Corresponding Author, Changfu ZOU, Chongqing Research Institute of China Coal Technology \& Engineering Group Corporation, Chongqing, China; E-mail: 3051617571@qq.com.
} 


\section{General Situation of Blasting Working Face and Source of Dust}

The roadway section of the 107 blasting working face in Dongling Coal Mine in Chongqing is rectangular, with a net section of $7.8 \mathrm{~m}^{2}$. The direct roof is sandy mudstone and fine sandstone, and the direct floor is sandy mudstone and sandstone. The anchor cable is used for steel support. The coal seam is stable, with an average coal thickness of $3.2 \mathrm{~m}$ and a coal seam inclination angle of $4.5^{\circ}-6.9^{\circ}$. It is driven by blasting. The process is relatively simple, and it is a low gas mine. The tunnel adopts press-in ventilation, and there is no other dust-proof equipment in the tunnel. Through actual observation and measurement on site, it is found that the main dust-producing process of coal tunnel blasting face is blasting operation. After the blasting of the working face, the dust fills the entire throwing zone instantly, and a large amount of dust is generated in a short time with gun smoke. The instantaneous mine dust concentration is very high, and the throwing zone and other sections of the roadway have a concentration difference, which is caused by wind current and dust concentration gradient. Under the action of, the dust spreads out of the roadway. After a period of time, the large particles of dust in the throwing zone settle, and the small particles of dust and gun smoke spread to other spaces of the roadway with the wind [7-10]. The instantaneous dust concentration can reach $610 \sim 790 \mathrm{mg} / \mathrm{m}^{3}$ after the blasting of the driving roadway, with a high degree of dispersion, and the dust produced by blasting diffuses rapidly with the expansion movement of the blasting air wave, and the pollution impact range can reach several hundred meters, and a large amount. The fine dust is difficult to settle and suspend in the air of the roadway for a long time, which directly endangers the health of workers. At the same time, the use of ventilation and dust removal requires a long time for dust removal, which seriously affects the progress of tunnelling. Therefore, the focus of dust prevention on the blasting face should be placed on the blasting process.

\section{Law of Dust Diffusion in Blasting Work}

The dust and gun smoke produced after the explosive blasting of the blasting working face spreads and migrates out of the roadway with the wind flow, and the dust concentration gradually decreases and is diluted by the wind flow. Under the condition of air flow of $1.5 \mathrm{~m} / \mathrm{s}$, the dust concentration of $1.5,3,5$, and 10 minutes after firing was tested at a position $60 \mathrm{~m}$ from the front of the blasting face. The test results are shown in figure 1 .

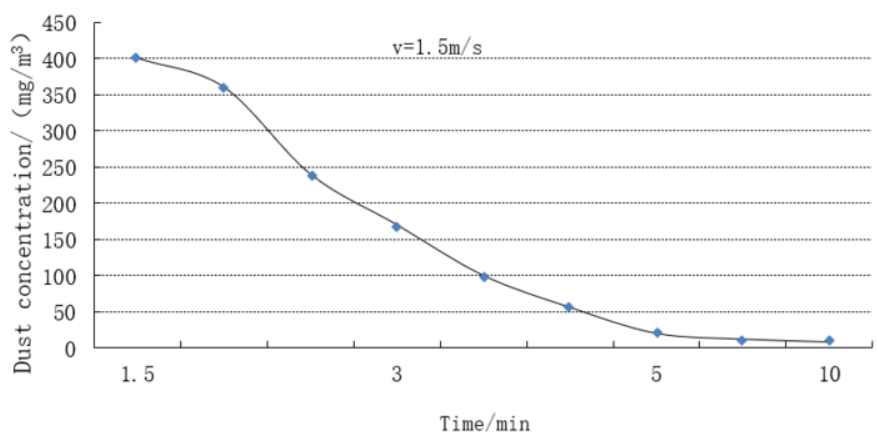

Figure 1. Dust concentration curve at $60 \mathrm{~m}$ from the working face. 
Because the dust diffusion speed is affected by the wind speed of the roadway, the dust distribution in time and space will change with the change of wind speed. The dust concentration in the roadway was measured under different wind speed conditions. The measuring point was $60 \mathrm{~m}$ away from the blasting face and the wind speed at the measuring point at $1,1.5,2,2.5 \mathrm{~m} / \mathrm{s}$ at $0.5,1,2$, and 3 minutes after the shot was fired. The dust concentration under the conditions, the measurement results are shown in figure 2 .

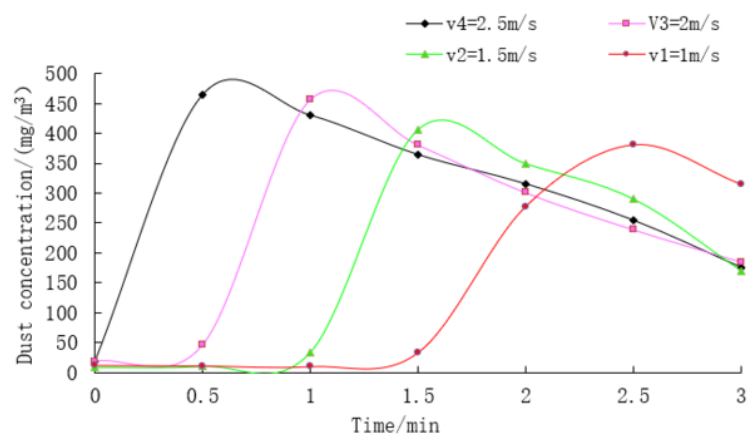

Figure 2. Dust concentration curve at measuring point of blasting roadway.

It can be seen from the test results that the higher the wind speed in the roadway, the faster the dust and gun smoke dissipate. However, when the wind speed in the roadway is $2.5 \mathrm{~m} / \mathrm{s}$, the dust concentration in the roadway is higher than that under other wind speed conditions. It is because when the wind speed is high, the air current will raise the dust on the two walls of the roadway and the frontward settlement again, resulting in a higher dust concentration as a whole; when the wind speed is $1 \mathrm{~m} / \mathrm{s}$, the dust and gun smoke in the roadway are not easy to dissipate, and the duration Longer, therefore, the wind speed of the roadway should be 1.5-2 m/s [11-12]. At the same time, according to the dust concentration and diffusion law of the blasting face, the air supply of the face should not only meet the air volume specified in the regulations, but also meet the allowable concentration of diluted dust, that is, the dust concentration does not exceed $0.5 \mathrm{mg} / \mathrm{m}^{3}$, Then the air volume of the working face is :

- $\quad \mathrm{Q}=\mathrm{G} /\left(\mathrm{C}-\mathrm{C}_{0}\right)$, where $\mathrm{G}$ - Dust generation intensity, $\mathrm{mg} / \mathrm{min}$;

- $\mathrm{C}$ - Dust concentration after dilution, $\mathrm{C}=0.5 \mathrm{mg} / \mathrm{m}^{3}$;

- $\mathrm{C}_{0}$ - Original dust concentration, $\mathrm{mg} / \mathrm{m}^{3}$; so the optimal dust exhaust wind speed $\mathrm{V}$ is:

- $\quad \mathrm{V}=\mathrm{Q} / \mathrm{S}$

According to calculation and test results, the best dust exhaust wind speed at the 107 blasting face of Dongling Coal Mine in Chongqing is $1.5 \mathrm{~m} / \mathrm{s}$.

\section{Research on Dust Control Technology of Blasting Work}

\subsection{Blasting High Pressure Spray for Dust Reduction}

The blasting automatic high-pressure spray dust reduction technology mainly uses the blasting shock wave to control the high-pressure spray system. When the blasting shock 
wave hits the sensor, the solenoid valve is controlled to work, the high-pressure spray pump is turned on, and the high-pressure water flow above $12 \mathrm{MPa}$ is delivered to the nozzle fixed on the spray rack through the high-pressure water pipe. The formation of high-density fine mist particles fills the tunnelling head after the blasting, forming a water mist barrier, which can effectively prevent the dust generated after blasting from spreading out, and achieve the effect of dust reduction and elimination of gun smoke. In addition, the high-pressure spray also has a certain electrostatic charge, and the electrostatic attraction of the dust makes it have a good purification effect on the fine dust that is difficult to purify. The high-pressure spray dust reduction system is shown in figure 3 . Through the test, the high-pressure spray dust reduction efficiency reaches over $85 \%$.

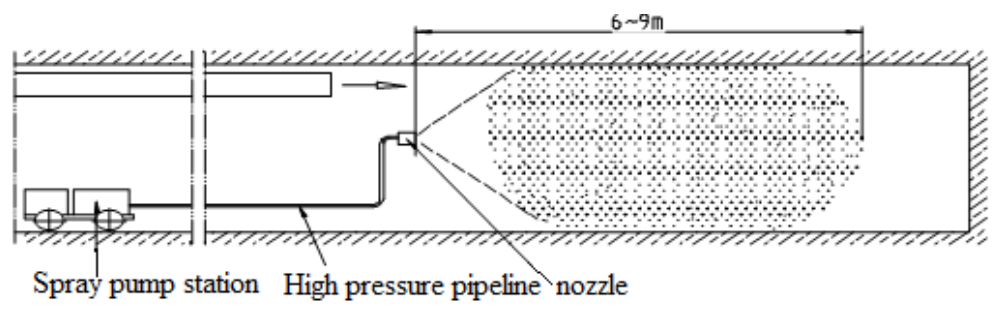

Figure 3. High pressure spray dust suppression system.

\subsection{Efficient Water Cannon Mud for Dust Reduction}

The essence of water cannon mud dust reduction is to replace or partially replace the cannon mud with water-filled plastic bags to fill the blasthole. The water bag ruptures during blasting. Under the action of the high temperature and high pressure explosion wave, most of the water is vaporized and then condensed again. The fine mist droplets are in contact with the mineral dust generated at the same time, forming condensation nuclei of the mist droplets or being wetted by the mist droplets to play a dust reduction effect. This method can not only reduce the large amount of coal dust produced after blasting, but also effectively reduce the concentration of toxic and harmful gases. It is an active and effective dust prevention technology.

Due to the high surface tension of pure water, it is not easy to atomize or the degree of atomization is not high after blasting, so the coal dust cannot be wetted sufficiently, and a better dust reduction effect cannot be achieved. Therefore, through experimental research, after adding a dust suppressant to the water, the surface tension of the solution is reduced, and the degree of atomization, wetting ability and the ability to capture dust are improved. The specific gravity of the high-efficiency water cannon mud aqueous solution is larger than that of pure water. It has more bursting force, so when the vaporized solution re-condenses into very fine mist droplets and collides with the mineral dust, the specific gravity of the condensation nucleus or the dust moistened by the mist droplets is larger, and the relative velocity during the collision It is larger, so its dust reduction effect is $60 \%$ higher than that of ordinary water cannon mud, as shown in figure 4. 


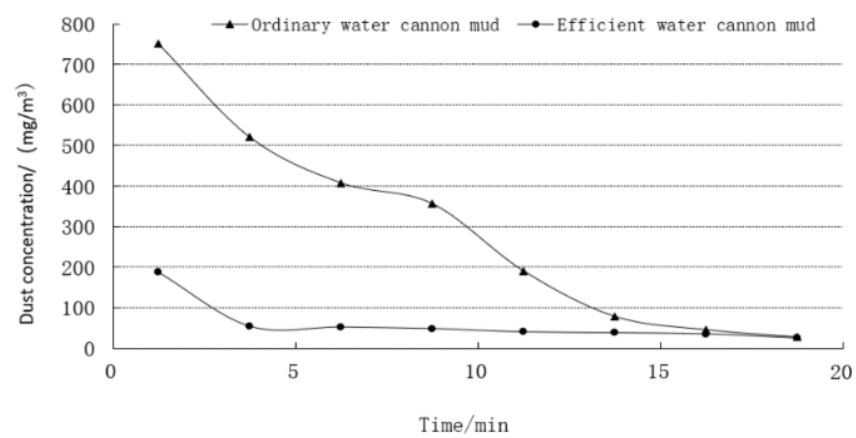

Figure 4. Comparison of the relationship between dust concentration and time when using water gun mud.

\subsection{Roadway Air Flow Purification Technology}

The dust concentration sensor is used to monitor the dust concentration in the workplace in real time, and the upper and lower limits of the dust concentration of the control spray are set in the over-limit spray control box or the monitoring system host. When the dust concentration exceeds the upper limit, the control box controls the solenoid valve to open Spray; below the lower limit, stop spraying. During the spraying of the device, if a person passes through the spraying location, the light control sensor will transmit the detected signal to the spray dust reduction device, and the device will automatically delay spraying. The intelligent spray is realized, which can reduce the dust concentration in the roadway and improve the working environment. The system is shown in figure 5 .

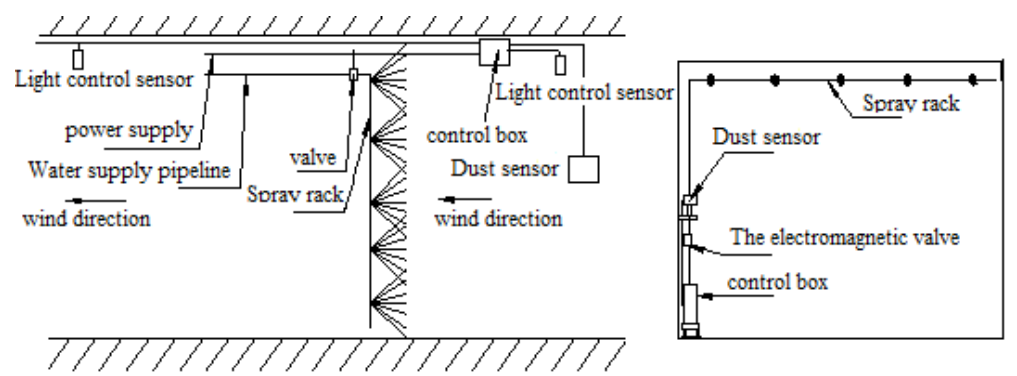

Figure 5. Dust concentration over-limit spray system.

\section{Dust Suppression Effect Analysis}

According to the general situation of the roadway in the 107 blasting working face of Dongling Coal Mine in Chongqing, 4 sections of high-efficiency water cannon mud are installed during the blasting charge, a high pressure spray dust removal system is arranged $10 \mathrm{~m}$ away from the working face, and a dust concentration over limit spray dust removal system is arranged $45 \mathrm{~m}$ away from the roadway to form a set of comprehensive dust control system, through the field observation, the coal dust in the airflow of the blasting face has been greatly reduced after adopting the above comprehensive dust control measures. The dust concentration was tested at the height of the operator's 
breathing belt by the filter membrane mass method, and the test time was 5 minutes. The test results were shown in table 1 .

Table 1. Dust concentration test table.

\begin{tabular}{|c|c|c|c|c|}
\hline Type of dust & t Sampling location & $\begin{array}{l}\text { Original dust } \\
\text { concentration }\left(\mathrm{mg} / \mathrm{m}^{3}\right)\end{array}$ & $\begin{array}{l}\text { Dust concentration after high- } \\
\text { pressure spray dust control } \\
\left(\mathrm{mg} / \mathrm{m}^{3}\right)\end{array}$ & $\begin{array}{l}\text { Dust reduction } \\
\text { efficiency }(\%)\end{array}$ \\
\hline \multirow{2}{*}{$\begin{array}{l}\text { Total dust } \\
\text { Breathable } \\
\text { dust }\end{array}$} & \multirow{2}{*}{$\begin{array}{l}20 \mathrm{~m} \text { away from } \\
\text { the working face }\end{array}$} & 348 & 18 & $94.8 \%$ \\
\hline & & 113 & 9 & $92.0 \%$ \\
\hline
\end{tabular}

At the same time, in order to continuously investigate the dust removal effect, a dust concentration sensor was installed at a distance of $60 \mathrm{~m}$ from the working face to monitor the dust concentration online. The monitoring curve is shown in Figure 6. It can be seen from the curve that after comprehensive dust prevention measures were taken, the dust was eliminated from the source, and the way the dust spread with the wind was successfully cut off, and good results were achieved.

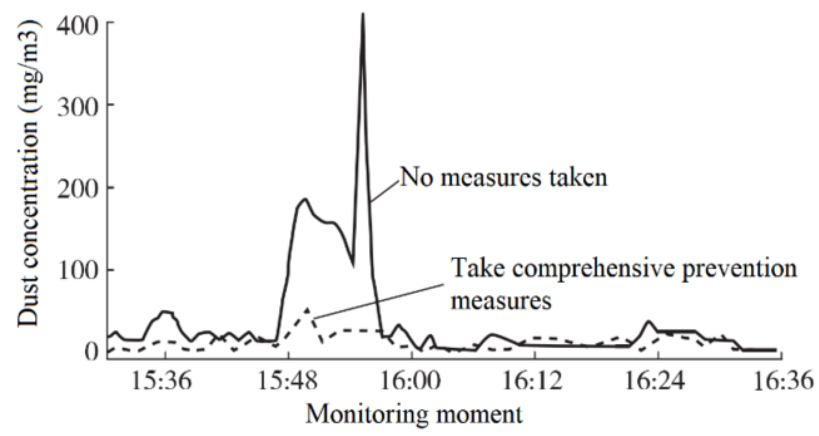

Figure 6. Dust concentration monitoring curve at $45 \mathrm{~m}$ from the working face.

\section{Conclusion}

(1) Ventilation and dust removal on blasting working face is an important measure for dust prevention and control. Generally, the best dust discharge wind speed for blasting working face is $1.5 \mathrm{~m} / \mathrm{s}$.

(2) Adding a dust suppressant to the water cannon mud reduces the surface tension of the solution, improves the degree of atomization, wetting ability and the ability to capture dust, and its dust reduction effect is about $60 \%$ higher than that of ordinary water cannon mud.

(3) The mist produced by high-pressure spray has high velocity, small particle size and a large amount of static charge, which can obtain high dust reduction efficiency with a small water consumption, and is the main ideal measure for dust reduction in blasting working faces.

(4) The installation of over-limit automatic spray dust suppression water curtains in the roadway can keep the dust concentration of the roadway below the standard concentration, which plays a very important role in the secondary flying of floating coal dust and the control of dust production in other operations. 


\section{References}

[1] Tang M, Liu R, Wang P, et al. 2015 Experimental study of high-pressure spray atomization characteristics and dust suppression efficiency Mineral Engineering Research 30 (1) 76-80.

[2] Neuman C M, Boulton J W and Sanderson S 2009 Wind tunnel simulation of environmental controls on fugitive dust emissions from mine tailings Atmos Environ. 43 520-529. https://doi.org/10.1016/j.atmosenv.2008.10.011.

[3] Zhang B 2007 Mining discussion on comprehensive dust control technology in local small coal Mines Safety \& Environmental Protection 34 (2) 67-69.

[4] Li R, Guo S, Xu X, et al. 2005 Practice and application of comprehensive dust prevention technology in fully mechanized excavation face Mining Safety \& Environmental Protection 32 (5) 64-65.

[5] Parra M, Villafruela J, Castro F and Mendez C 2006 Numerical and experimental analysis of different ventilation systems in deep mines Build Environ. 41 87-93. https://doi.org/10.1016/j.buildenv.2005.01.002.

[6] Wang Y, Liu B and Ji W 2012 Research on dust control of blasting work Shandong Coal Science and Technology (4) 206-207.

[7] Zou C, Liu Y, Ma W, et al. 2014 Study on dust generation and movement laws in fully-mechanized heading face Mining Safety \& Environmental Protection 41 (6) 26-28.

[8] Yao Y, Cheng W, Nie W, et al. 2011 Numerical simulation of dust concentration distribution in comprehensive excavation work Mining Safety \& Environmental Protection 38 (3) 21-23.

[9] Song Z, Ying Y and Tiang J 2010 Application and practice of dust prevention technology in blasting face Shandong Coal Science and Technology (1) 191-192.

[10] Zhang S, Liu Y, Zhou R, et al. 2010 Dust distribution law of excavation work and test of dust control technology Mining Safety \& Environmental Protection 37 (2) 30-33.

[11] Zhu L, Nie W, Zhou G, et al. 2014 Research and application of the optimal selection method of nozzle used in coal mine Industrial Safety and Environmental Protection 40 (9) 7-10.

[12] Toraño J, Torno S, Menéndez M and Gent M 2011 Auxiliary ventilation in mining roadways driven with roadheaders: Validated CFD modelling of dust behaviour Tunn. Undergr. Space Technol. 26 201-210. https://doi.org/10.1016/j.tust.2010.07.005. 